\title{
THE VERTICAL DISTRIBUTION OF CHLOROPHYLL ${ }^{1}$
}

\author{
By J. H. Steele ${ }^{2}$ and C. S. Yentsch \\ Woods Hole Oceanographic Institution
}

(Text-figs. I-7)

The vertical distribution of chlorophyll in the sea generally shows a maximum concentration at a depth which may vary from at or just below the surface, to near or below the bottom of the euphotic zone. The easiest distributions to explain are those where the maximum chlorophyll concentration is at or very near the surface. These are found when a population is photosynthesizing actively during the first stages of an outburst, and the distribution corresponds roughly with the change with depth of the photosynthetic rate (Steele, I957). However, these form a small proportion of observations, probably because outbursts are usually restricted to comparatively short periods of time. The more usual distributions show a maximum in the chlorophyll concentrations well below the surface and below the depth of maximum photosynthesis.

Such features are normally explained by the sinking of plants and a sinking rate constant with dzpth is used in the mathematical models of Riley, Stommel \& Bumpus (1949) to explain some observed patterns of vertical distribution. However, on the basis of their model, the chlorophyll maximum must occur above the compensation depth. Although many of the maxima are of this type, there are as many which occur below or just at the compensation point and so are not explicable by a constant sinking rate. In particular, this feature is the dominant one in the distributions found during summer by the Woods Hole Oceanographic Institution in waters off New York (Ketchum, Ryther, Yentsch \& Corwin, 1957; Ryther \& Yentsch, 1958; Yentsh \& Vaccaro, 1958). This work is concerned with a possible explanation for such distributions.

\section{THE OBSERVED DISTRIBUTIONS}

Two examples of chlorophyll distribution in which the maximum concentration was found near the compensation depth are given in Table I, which includes simultaneous observations of the ${ }^{14} \mathrm{C}$ in situ rate of photosynthesis, and the concentrations of nitrate and phosphate in water. Crawford station

\footnotetext{
${ }^{1}$ Contribution no. 1078 from the Woods Hole Oceanographic Institution. This work was supported in part by A.E.C. Contract AT (30-I) I9I8.

${ }_{2}^{2}$ Marine Laboratory, Aberdeen, Scotland. Visiting investigator under a W.H.O.I. fellowship during the autumn of 1958 .
} 

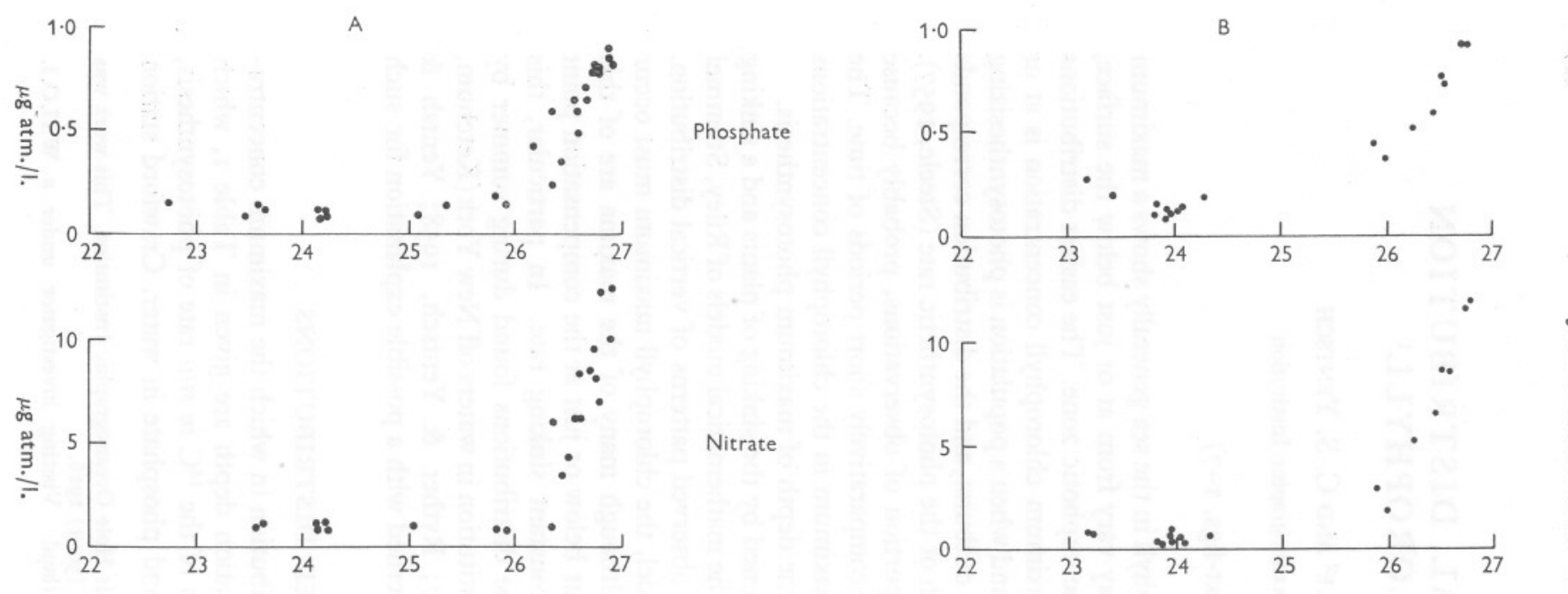

焦
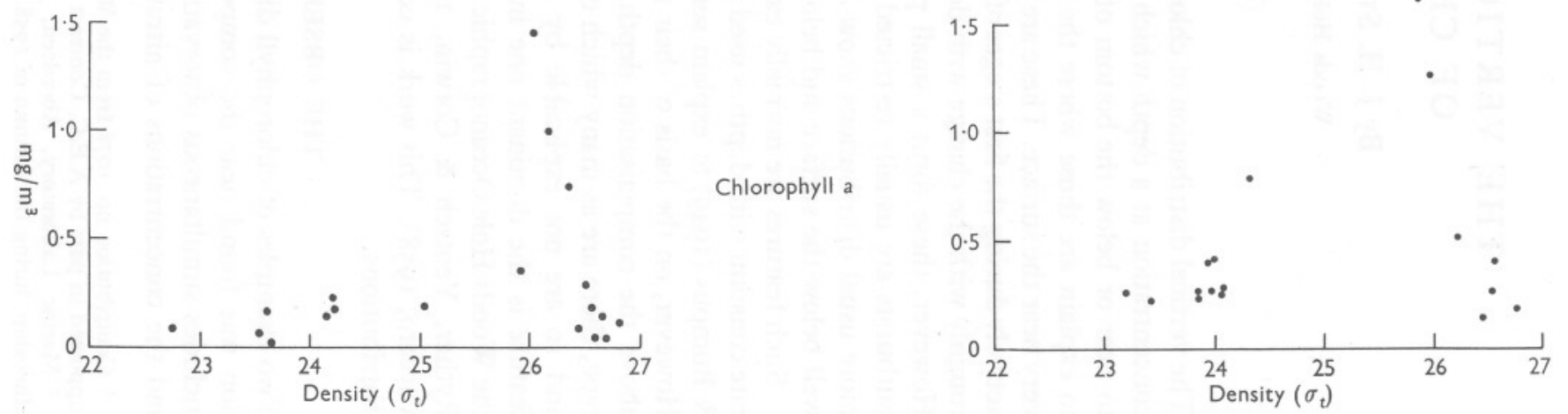

Fig. I. Observed conditions in July (A) and September (B) 1957. 
no. I94 was occupied where the total depth was $3000 \mathrm{~m}$ and the other station (Crawford no. 209) was in water with a depth of $40 \mathrm{~m}$.

For four offshore stations in depths greater than $1000 \mathrm{~m}$ the relations between nitrate, phosphate and chlorophyll in July and September 1957 are shown in Fig. I by plotting these against density. The July chlorophyll values suggest a very sharp peak at $\sigma_{t}=26$, but the September values do not have enough observations in the middle range of density to determine the sharpness. In all cases the high values are found at $50 \mathrm{~m}$, although there are some stations at which no pronounced peak is found; this is probably due to the wide spacing of the sampling depths and the comparative sharpness of the peak. The occurrence of the peak in both July and September and the similarity of the nutrient distributions suggest that conditions during this interval can be considered to approximate a steady state. Perhaps the most convincing evidence that the depth of the mean daily euphotic zone is near these peaks is shown by the concentrations of nutrients which increase sharply at about the same depth. The ${ }^{14} \mathrm{C}$ data can be used to define the depth distribution of production. It appears that the compensation point at station 194 must be just below $50 \mathrm{~m}$ and the I \% light level was found at $58 \mathrm{~m}$. At the shallower station the compensation depth was between 20 and $30 \mathrm{~m}$ and the $\mathrm{I} \%$ level was at $19 \mathrm{~m}$.

\section{THEORETICAL DISTRIBUTIONS}

The purpose of these theoretical considerations is to show how the sinking rate interacts with other factors affecting vertical distribution of plants, and how a variable sinking rate can produce idealized distributions similar to those described above. These concepts do not explain how this decreasing sinking rate could be brought about and since the main possible explanation is in terms of the effect of density, the theoretical relations between size, shape and density will be considered.

Since sinking is only one factor which can affect the vertical distributions of plants, the effects of variations in this rate must be linked with other factors - photosynthesis and respiration of the plants, grazing by herbivores and vertical mixing of the water. These five variables have been combined in a mathematical form by Riley et al. (1949). Assuming a sinking rate that is constant with depth, $z$, the equation for a steady state is

$$
A \frac{\partial^{2} p}{\partial z^{2}}-v \frac{\partial p}{\partial z}+(w-h) p=0
$$

where $p$ is the plant concentration, $A$ is the coefficient of eddy diffusivity, $v$ is the sinking rate, $w$ is the photosynthetic rate and $h$ is the combined effect of grazing and plant respiration. For a maximum concentration of plants, $p$

$$
\frac{\partial p}{\partial z}=0 \text { and } \frac{\partial^{2} p}{\partial z^{2}}=\left(\frac{h-w}{A}\right) p<0 .
$$


The latter holds only for $w>h$, that is when the photosynthetic rate exceeds the combined loss due to respiration and grazing. Thus for a constant sinking rate the maximum must occur above the mean daily compensation depth. This conclusion is independent of variations with depth in grazing or mixing. (Although it can be seen from this how decreased mixing tends to increase the sharpness of the maximum.)

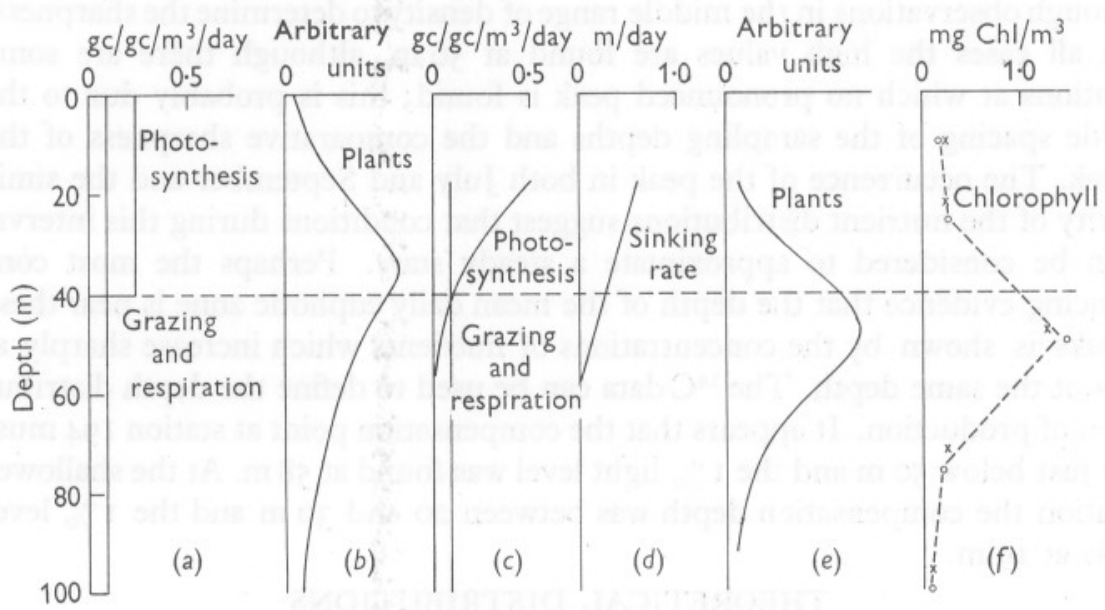

Fig. 2. ( $a$ and $b$ ) Conditions from the theory of Riley et al. (1949), using a constant sinking rate. $(c, d, e)$ Conditions with a variable sinking rate. $(f)$ Data from Station 194 .

On this basis, Riley et al. (1949) constructed profiles of vertical plant distributions. With their solution, the deepest possible maximum will be given when a constant photosynthetic rate throughout the euphotic zone is assumed, Fig. 2(a). Constant sinking, grazing and respiration rates throughout the water column are assigned. With a sinking rate of $3 \mathrm{~m} /$ day and numerical values for the other factors corresponding roughly to the offshore conditions, the example in Fig. $2(b)$ is obtained. Its disadvantage is that the form of the photosynthetic coefficient is unrealistic and biases the plant maximum downwards.

If a variable sinking rate is introduced, (I) takes the form

$$
A \frac{\partial^{2} p}{\partial z^{2}}-v \frac{\partial p}{\partial z}+\left(w-h-v^{1}\right) p=0,
$$

where $v^{1}$ is the rate of change of the sinking rate. Then a maximum occurs when

$$
\frac{\partial p}{\partial z}=0 \text { and } \frac{\partial^{2} p}{\partial z^{2}}=\left(\frac{h+v^{1}-w}{A}\right) p<0,
$$

i.e. when $-v^{1}>h-w$. This permits a maximum below the foot of the euphotic zone. 
Thus a decreasing sinking rate is not only a possible means of securing a maximum at or below the compensation depth, which is fairly obvious; it is also the only way it can be achieved in terms of the variables considered here.

As an example of the kind of profile that can be obtained in the thermocline region offshore, a solution of (2) was constructed with a linearly decreasing sinking rate and a more realistic photosynthetic rate as shown in Fig. $2(c)$ and $(d)$. The zero sinking rate has been set at $58 \mathrm{~m}$ so that the balance between photosynthesis and grazing plus respiration, the compensation depth of the community, occurs at nearly the same depth as in Fig. 2(a) and is indicated by a dashed line. This leads to the profile given in Fig. 2(e). The data from station 194 are shown for comparison in Fig. $2(f)$. This example shows how a decreasing sinking rate depresses the chlorophyll maximum to below the compensation depth of the community. It also provides a value for the decrease in sinking rate that is required to give a profile similar to those observed.

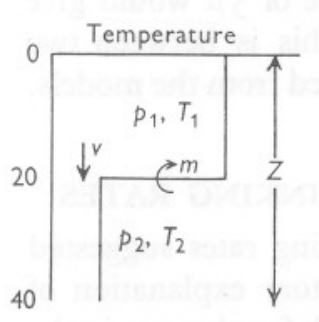

Fig. 3

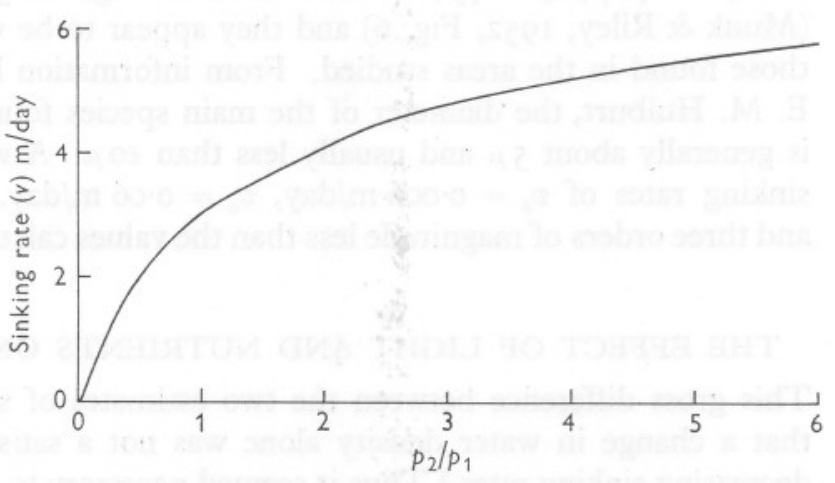

Fig. 4

Fig. 3. Idealized inshore distribution of temperature $\left(T_{1}, T_{2}\right)$, plants $\left(p_{1}, p_{2}\right)$, zooplankton $(Z)$ with mixing $(m)$ and sinking $(v)$ between the layers.

Fig. 4. Relation between sinking rate and ratio of plant concentrations in lower and upper layers.

A second theoretical example corresponding to inshore conditions can be constructed by considering a sea $40 \mathrm{~m}$ deep divided into two equal layers, Fig. 3, with a positive sinking rate $v$ in the upper layer and zero rate in the lower; this gives the relation between $v$ and the ratio $p_{2} / p_{1}$ shown in Fig. 4. It can be seen that ratios of three to six which is around the observed range are obtained for a sinking rate of $5-6 \mathrm{~m}$ /day which is about the same value as that deduced for the upper layers in the offshore example. These values are realistic in terms of previously calculated sinking rates (Riley et al. 1949; Steele, 1956, 1957; Steemann-Nielsen \& Jensen, 1957).

In both areas the density increase across the thermocline is in the range 
$0.002-0.003$. From Munk \& Riley (1952) the relations between the sinking rates, size of the plants, and the density difference between the plants and the water, for the simple shapes, spheres and cylinders, can be expressed approximately as

$$
\begin{aligned}
& v_{s}=\frac{\Delta p d_{s}^{2}}{\text { Io }} \text { for a sphere (Stokes Law), } \\
& v_{c}=\Delta p d_{c}^{2} \text { for a cylinder, }
\end{aligned}
$$

where $v_{s}, v_{c}$ are the sinking rates $\left(\mathrm{m} /\right.$ day) and $d_{s}, d_{c}$ are the diameters $(\mu)$ of spheres and cylinders, respectively; $\Delta p$ is the density difference between the cell and the water.

Assuming the extreme case considered earlier, when the cells are neutrally buoyant in the lower layers, then the approximate sinking rates are obtained by putting $\Delta p=0.0025$. For a sinking rate of $5 \mathrm{~m} /$ day the required diameters are $d_{s}=\mathrm{I} 40 \mu, d_{c}=45 \mu$. These values are high for generally observed sizes (Munk \& Riley, I952, Fig. 6) and they appear to be very much higher than those found in the areas studied. From information kindly provided by Dr E. M. Hulburt, the diameter of the main species found during the summer is generally about $5 \mu$ and usually less than Iо $\mu$. A value of $5 \mu$ would give sinking rates of $v_{s}=0.006 \mathrm{~m} /$ day, $v_{c}=0.06 \mathrm{~m} /$ day. This is between two and three orders of magnitude less than the values calculated from the models.

\section{THE EFFECT OF LIGHT AND NUTRIENTS ON SINKING RATES}

This gross difference between the two estimates of sinking rates suggested that a change in water density alone was not a satisfactory explanation of decreasing sinking rates. ${ }^{1}$ Thus it seemed necessary to look for changes in the density of the cells themselves as a possible explanation. It seemed probable that a decrease in sinking rate could be produced as a result of recovery of the plant cells from nutrient deficiencies. The depth at which maximum chlorophyll is observed is frequently within the thermocline, where nutrient concentrations increase with increasing depth. Gross \& Zeuthen (I948) have observed variations in the sinking rates of diatoms under different culture conditions. It is a common phenomenon for the algal culturist to observe that old cultures settle out more rapidly than do young actively growing cultures.

To examine the effects of light and nutrients on the sinking rate we have conducted the following experiments. Cultures of the diatom Skeletonema costatum (Grev.) were grown in $4 \mathrm{~B}$ media (Yentsch \& Vaccaro, I958) at $18^{\circ} \mathrm{C}$ in constant optimal light intensity. Periodically this culture was

${ }^{1}$ Jerlov (1959) by the same reasoning given earlier noted the necessity of decreasing sinking rates to explain deep particle maxima. However, he had no information on the particle sizes and accepted density changes in the water as sufficient explanation. 
sampled and the sinking rate of the cells measured. Approximately 30 c.c. of well-agitated culture were placed in a $5 \mathrm{~cm}$, large volume, optical cuvette. In the first experiment clumping was removed with a Potter-Eluehjehm homogenizer using a Teflon pestle. Optical density measurements were made in a Beckman DU spectrophotometer at a wave-length of $750 \mathrm{~m} \mu$. Decreases in the optical density at this wave-length, resulting from cells settling out of the light path, were measured at regular intervals over a period of $\mathrm{I} h$ (Fig. 5). The percentage decrease of the optical density during the hour is used as a measure of relative sinking rate.

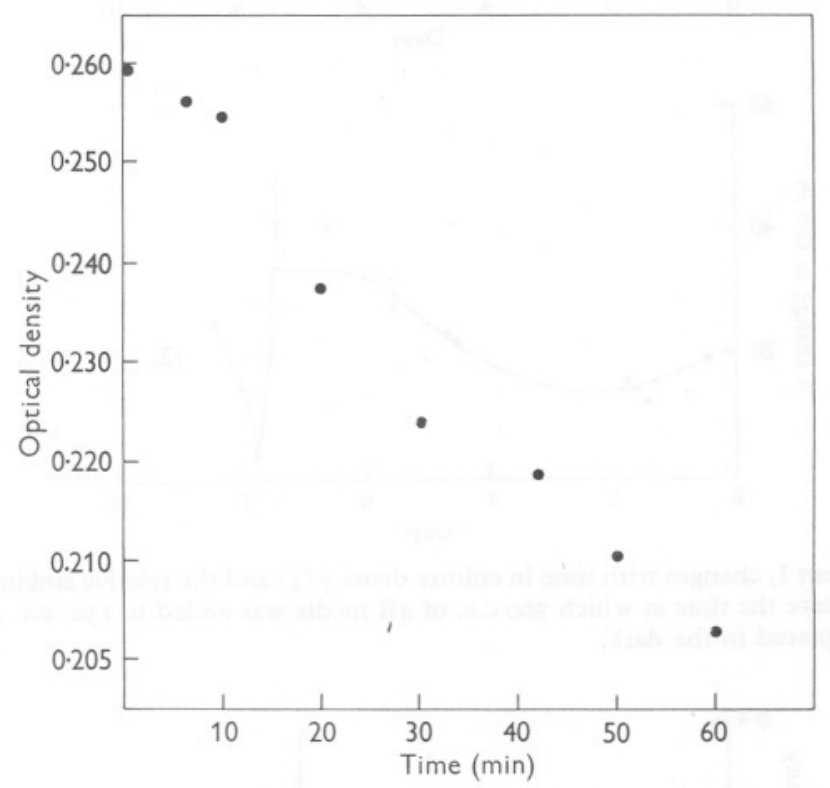

Fig. 5. Changes in optical density of a culture in a cuvette, resulting from cells settling.

The results of two experiments show that the settling rate of actively dividing cells was approximately one-half the rate of slowly dividing, senescent cells. In the first experiment, Fig. 6, an aliquot of the culture was removed between the seventh and eighth day, enriched with nutrients, and placed in the dark. During the first half day the cells in the dark settled more slowly than the illuminated cells, after which the settling rate increased.

In the second experiment three aliquots of the illuminated culture were removed between the third and fourth day of growth. Two of these were enriched, one was darkened, the other illuminated. The third aliquot was not enriched but was placed in the dark. In all three aliquots the settling rate of cells was decreased relative to that of the original culture. The lowest settling 

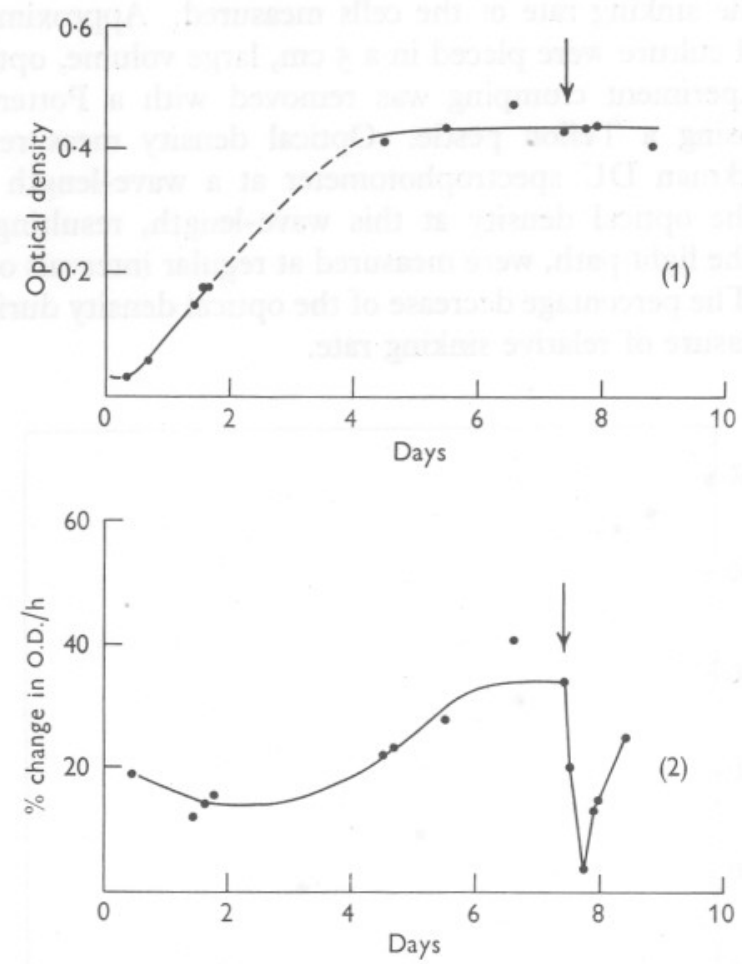

Fig. 6. Experiment I, changes with time in culture density (I) and the relative sinking rate (2). The arrows indicate the time at which 300 c.c. of $4 \mathrm{~B}$ media was added to I50 c.c. aliquot of the culture and placed in the dark.
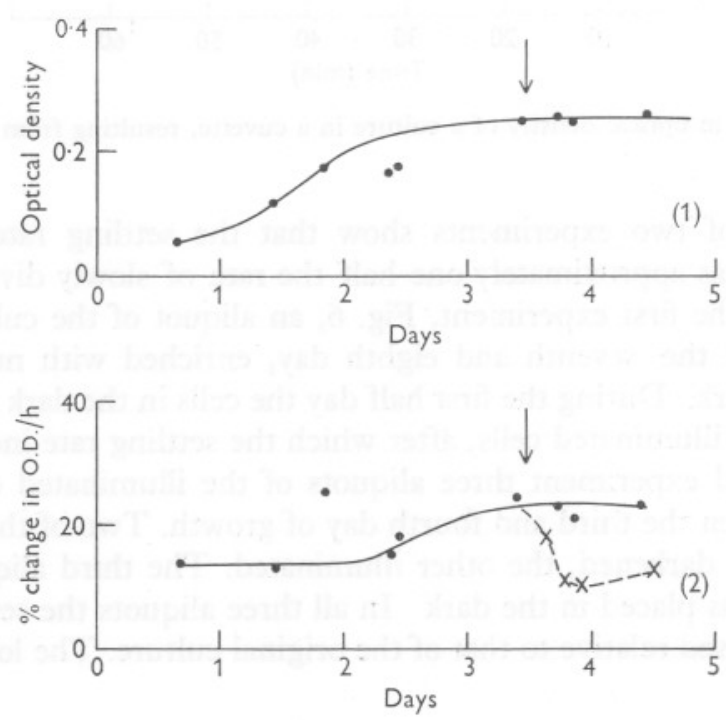

Fig. 7. Experiment II, changes with time in culture density (I) and relative sinking rate (2). The arrows indicate the time at which 300 c.c. of $4 \mathrm{~B}$ media was added to 150 c.c. aliquot of the culture and placed in the dark. 
rate occurred in the enriched darkened aliquot, Fig. 7, broken line, with the others intermediate between this and the control.

The results of these experiments show that older cells settle faster than do rapidly growing cells. Furthermore, when old cells are enriched in the dark, the settling rate is considerably reduced.

\section{DISCUSSION}

From a mathematical model which used as parameters of the phytoplankton environment, photosynthesis, respiration, grazing and eddy diffusion, we have concluded that a decreased sinking rate is needed to produce chlorophyll maxima at or below the base of the euphotic zone. Density differences observed throughout the water column appeared unable to explain these vertical distributions, and so we postulated the concept that the chlorophyll maxima are due to a decrease in sinking rate of the plants themselves caused by their entry into the dark, nutrient-rich waters found at the foot of the euphotic zone. The justification of this rather tentative hypothesis is that it predicted an experimental result.

Our experimental results show that as growth slows down, the cells sink more rapidly. When the deficient cells are re-enriched and placed in the dark, their sinking rate decreases rapidly. The picture that emerges is one where the general physiological condition of the cell and its buoyancy are closely related, as Gross \& Zeuthen (1948) have also suggested. On this basis, seasonal variations in the vertical distribution of chlorophyll can be explained. For example, during early spring when nutrients are sufficient, phytoplankton cells would tend to have a low sinking rate, and populations undergoing rapid growth would tend to accumulate near the surface. In late summer when nutrients are depleted in the surface waters, phytoplankton would sink and accumulate in the nutrient rich water at the base of the euphotic zone. Here the assimilation of nutrients which can proceed in the dark (Ketchum, 1939) would, as our experiments show, decrease the sinking rate of the phytoplankton cells.

\section{SUMMARY}

Theoretical considerations of the occurrence of chlorophyll maxima at the foot of the euphotic zone show that a decreasing sinking rate is necessary to explain this feature but that the required decrease could not be obtained from density changes in the water alone. It is thought that the cells themselves might increase their buoyancy when they reach dark, nutrient-rich waters, and this has been confirmed by two experiments in which deficient laboratory cultures of Skeletonema costatum were re-enriched in the dark and decreased their sinking rate considerably. 


\section{REFERENCES}

Gross, F. \& ZeUthen, E., I948. The buoyancy of plankton diatoms; a problem of cell physiology. Proc. Roy. Soc. B, Vol. 135, pp. 382-9.

Jerlov, N. G., 1959. Maxima in the vertical distribution of particles in the sea. DeepSea Res., Vol. 5, pp. I73-84.

Ketchum, B. H., I939. The development and restoration of deficiencies in the phosphorus and nitrogen composition of unicellular plants. F. cell. comp. Physiol., Vol. I3, pp. 373-81.

Ketchum, B. H., Ryther, J. H., Yentsch, C. S. \& CoRwin, N., I957. Productivity in relation to nutrients. Rapp. Cons. Explor. Mer, Vol. I44, pp. I32-4I.

MunK, W. H. \& RILEY, G. A., I952. Absorption of nutrients by aquatic plants. F. mar. Res., Vol. II, pp. 215-40.

Riley, G. A., STOMmel, H. \& Bumpus, D. F., I949. Quantitative ecology of the plankton of the western North Atlantic. Bull. Bingham oceanogr. Coll., Vol. 12, No. 3, pp. I-I69.

RYTHER, J. H. \& Yentsch, C. S., 1958. Primary production of continental shelf waters off New York. Limnol. and Ocean., Vol. 3, pp. 327-35.

Steele, J. H., I956. Plant production on the Fladen ground. F. mar. biol. Assoc. U.K., Vol. 35, pp. I-33.

1957. Production studies in the northern North Sea. Rapp. Cons. Explor. Mer, Vol. I44, pp. 79-83.

Steemann-Nielsen, E. \& Jensen, A., I957. Primary oceanic production. The autotrophic production of organic matter in the ocean. 'Galathea' Rep., Vol. I, pp. $49-136$.

Yentsch, C. S. \& VACCARo, R. F., I958. Phytoplankton nitrogen. Limnol. and Ocean., Vol. 3, pp. 443-8.

TABLE 1. EXAMPLES OF THE VERTICAL DISTRIBUTION OF CHLOROPHYLL, OF THE RATE OF PHOTOSYNTHESIS AND CONCENTRATION OF NUTRIENTS AT STATIONS WHERE THE MAXIMUM CHLOROPHYLL CONCENTRATIONS OCCURRED AT OR NEAR THE COMPENSATION DEPTH

\begin{tabular}{|c|c|c|c|c|}
\hline Depth $(\mathrm{m})$ & $\mathrm{Chl} a \mathrm{mg} / \mathrm{m}^{3}$ & $\begin{array}{l}{ }^{14} \mathrm{C} \text { in situ } \\
\text { measurements } \\
\mathrm{mg} \mathrm{C} / \mathrm{m}^{3} / \text { day }\end{array}$ & $\begin{array}{c}\mathrm{NO}_{3}-\mathrm{N} \\
\mu \mathrm{g} \text { atm. } / 1 .\end{array}$ & $\underset{\mu \mathrm{g} \text { atm. } / 1}{\mathrm{PO}_{4}-\mathrm{P}}$ \\
\hline \multicolumn{5}{|c|}{ Crawford station 194, July 1957} \\
\hline I0 & 0.18 & I. 8 & 0.53 & 0.09 \\
\hline 25 & 024 & $5 \cdot 2$ & 0.39 & 0.11 \\
\hline 50 & I.46 & 5.6 & 0.43 & 0.19 \\
\hline 75 & 0.19 & 0 & 6.00 & 0.59 \\
\hline 100 & 0.09 & 0 & $6 \cdot 20$ & 0.66 \\
\hline \multicolumn{5}{|c|}{ Crawford station 209, July 1957} \\
\hline 0 & 0.40 & $24 \cdot 0$ & 0.96 & 0.48 \\
\hline Io & 0.57 & $9 \cdot 3$ & 0.50 & 0.36 \\
\hline 20 & $I \cdot 62$ & $8 \cdot 7$ & I 17 & 0.54 \\
\hline 30 & 0.25 & 0 & $4 \cdot 50$ & $0.4 \mathrm{I}$ \\
\hline
\end{tabular}

